\title{
Next-generation sequencing analysis of lung and colon carcinomas reveals a variety of genetic alterations
}

\author{
SANDY CHEVRIER ${ }^{1}$, LAURENT ARNOULD $^{1,3}$, FRANÇOIS GHIRINGHELLI ${ }^{2,3,4}$, \\ BRUNO COUDERT $^{2}$, PIERRE FUMOLEAU ${ }^{2}$ and ROMAIN BOIDOT ${ }^{1,3,4}$
}

\author{
Departments of ${ }^{1}$ Biology and Pathology of Tumors and ${ }^{2}$ Medical Oncology, ${ }^{3}$ Platform of Transfer in Cancer Biology, \\ ${ }^{4}$ U866 Inserm Dijon, Centre Georges-François Leclerc, 21079 Dijon, France
}

Received April 24, 2014; Accepted June 4, 2014

DOI: $10.3892 /$ ijo.2014.2528

\begin{abstract}
The development of targeted therapies in cancer has accelerated the development of molecular diagnosis. This new cancer discipline is booming, with an increasing number of gene alterations to analyze in a growing number of patients. To deal with this fast-developing activity, current analysis techniques (Sanger sequencing, allelic discrimination and high resolution melting) take more and more time. In recent years, next generation sequencing (NGS) technologies have appeared and given new perspectives in oncology. In this study, we analyzed FFPE lung and colon carcinomas using the Truseq Cancer Panel, which analyzes the mutation hotspots of 48 genes. We also tested the use of whole-genome amplification before NGS analysis. NGS results were compared with the data obtained from routine diagnosis. All of the alterations routinely observed were identified by NGS. Moreover, NGS revealed mutations in the $K R A S$ and $E G F R$ genes in patients diagnosed as wild-type by routine techniques. NGS also identified concomitant mutations in EGFR and KRAS or BRAF mutations, and a 15-nt deletion in exon 19 of $E G F R$ in colon carcinomas. The study of the other genes sequenced in the Panel revealed 14 genes altered by 27 different mutations and three SNP with a possible role in cancer susceptibility or in the response to treatment. In conclusion, this study showed that NGS analysis could be used for the analysis of gDNA extracted from FFPE tissues. However, given the high sensitivity of this technology, highthroughput clinical trials are needed to confirm its reliability for the molecular diagnosis of cancer.
\end{abstract}

\section{Introduction}

Lung and colon cancers are among the main causes of death in developed countries. The life expectancy of patients is

Correspondence to: Dr Romain Boidot, Centre Georges François Leclerc, 1 rue du Professeur Marion, 21079 Dijon, France

E-mail: rboidot@cgfl.fr

Key words: next generation sequencing, colon cancer, lung cancer, mutations very limited, especially in metastatic disease. Nevertheless, in recent years, the development of targeted therapies (Tyrosine Kinase inhibitors or inhibitors of receptors which hyperactivate survival pathways) has shown great therapeutic promise. For example, patients with a mutated EGFR gene and wild-type $K R A S$ gene lung tumor are eligible for gefitinib therapy (1). In colon cancer, patients with wild-type $K R A S$ and $B R A F$ could be treated with panitumumab or cetuximab (2). In skin cancer, vemurafenib (3) or imatinib (4) can be used to treat mutated BRAF (V600E) or $c-K I T$ melanoma, respectively. As the efficacy of these targeted therapies depends on specific genetic abnormalities, molecular diagnosis has become essential for the treatment of cancers. Since 2008, molecular biology platforms have screened for genetic alterations in EGFR (exons 18-21), KRAS (codons 12 and 13) and $B R A F$ (codon 600). At the beginning, the gold standard was Sanger sequencing, but the technique has low sensitivity and is expensive. With the increasing number of samples and gene alterations to screen for, alternon-amplified techniques were developed. For example, allelic discrimination (5) was developed to screen for a specific mutation quickly at a relatively low price. In parallel, screening technologies, such as High Resolution Melting (6) or fragment analysis (for indel alterations), were developed to use with Sanger sequencing, but only in the presence of potential mutations in the region of interest. Over the years, the number of genes with genetic alterations that could be targeted by therapies has increased rapidly. This medical progress has led to the need for more and more molecular diagnoses. This need has now been met by the recent development of Next Generation Sequencing (NGS), which has revolutionized molecular diagnosis. Indeed, the sequencing capacity allows the analysis of dozens of genes on multiplexed samples. In this paper, we describe the results we obtained with the Truseq Cancer Panel. In addition to the routinely detected mutations, NGS analysis, thanks to its high sensitivity, revealed new mutations in routinely analyzed genes.

\section{Materials and methods}

Patients and DNA samples. Eighteen tissue samples with $>400 \mathrm{ng}$ gDNA (Table I) from patients treated at the Centre GeorgesFrançois Leclerc between 2009 and 2013 were randomly chosen. Genomic DNA was extracted from FFPE tissues 
Table I. Clinical details of studied patients.

\begin{tabular}{|c|c|c|c|}
\hline Patients & Organ of origin & Histology & Age (years) \\
\hline L1 & Lung & Keratinizing poorly differentiated squamous carcinoma & 61 \\
\hline $\mathrm{L} 2$ & Lung & Moderately differentiated adenocarcinoma & 67 \\
\hline L3 & Lung & Poorly differentiated adenocarcinoma & 62 \\
\hline $\mathrm{L} 4$ & Lung & Adenocarcinoma & 50 \\
\hline L5 & Lung & Adenocarcinoma & 69 \\
\hline L6 & Lung & Adenocarcinoma & 55 \\
\hline L7 & Lung & Mucus-secreting adenocarcinoma & 68 \\
\hline L8 & Lung & Acinar differentiated mucus-secreting adenocarcinoma & 86 \\
\hline $\mathrm{C} 1$ & Colon & Moderately differentiated adenocarcinoma & 55 \\
\hline $\mathrm{C} 2$ & Colon & Adenocarcinoma & 64 \\
\hline $\mathrm{C} 3$ & Colon & Moderately differentiated adenocarcinoma & 59 \\
\hline $\mathrm{C} 4$ & Colon & Adenocarcinoma & 72 \\
\hline C5 & Colon & Adenosquamous adenocarcinoma & 70 \\
\hline C6 & Colon & Poorly differentiated adenocarcinoma & 55 \\
\hline $\mathrm{C} 7$ & Colon & Adenocarcinoma & 80 \\
\hline $\mathrm{C} 8$ & Colon & Poorly differentiated adenocarcinoma & 72 \\
\hline C9 & Colon & Well differentiated infiltrating lieberkunien adenocarcinoma & 58 \\
\hline $\mathrm{C} 10$ & Colon & Colloidal adenocarcinoma & 67 \\
\hline
\end{tabular}

with either the QIAamp DNA mini kit (Qiagen, Heidelberg, Germany) or the Maxwell 16 FFPE Plus LEV DNA purification kit (Promega, Madison, USA). The samples had already been genotyped by allelic discrimination, fragment analysis and Sanger sequencing. Written consent was provided by all patients, and the researchers obtained authorization from the diagnostic centers to use the tumor samples.

Whole genome amplification. The Repli-g FFPE kit (Qiagen) was used to amplify $300 \mathrm{ng}$ of gDNA from patients L7 and L8: $10 \mu 1$ of gDNA solution were mixed with $8 \mu 1$ of FFPE buffer, $1 \mu \mathrm{l}$ of ligation enzyme and $1 \mu \mathrm{l}$ of FFPE enzyme. The solution was then incubated at $24^{\circ} \mathrm{C}$ for $30 \mathrm{~min}$, at $95^{\circ} \mathrm{C}$ for $5 \mathrm{~min}$ and then kept at $4^{\circ} \mathrm{C}$. The Repli-g master mix was prepared by mixing, per sample, $29 \mu \mathrm{l}$ of Repli-g Midi reaction buffer and $1 \mu \mathrm{l}$ of Repli-g Midi DNA Polymerase. This second mixture (30 $\mu \mathrm{l})$ was added to the gDNA solution. This solution was then incubated at $30^{\circ} \mathrm{C}$ for $2 \mathrm{~h}, 95^{\circ} \mathrm{C}$ for $10 \mathrm{~min}$ and kept at $4^{\circ} \mathrm{C}$. Amplified DNA was stored at $-20^{\circ} \mathrm{C}$. Thanks to this protocol, we obtained 6900 and $6400 \mathrm{ng}$ of amplified gDNA.

Preparation of libraries. Libraries were prepared with the Truseq Cancer Panel (Illumina, San Diego, USA) by following the manufacturer protocol. Briefly, 400-1250 ng of gDNA in $5 \mu \mathrm{l}$ water was hybridized with an oligo pool. Then, unbound oligos were removed, and extension-ligation of bound oligos was followed by PCR amplification. PCR products were cleaned and checked for quality using Tapestation analysis (Agilent). The PCR product size had to be around $350 \mathrm{bp}$. Before sequencing, the libraries were normalized by the normalization process of the Truseq Cancer Panel.
Sequencing with MiSeq device. As each library possessed a specific primer index combination (i5 and i7), the libraries were pooled for 2 sequencing runs (pool no. 1, 10 libraries; pool no. 2, 9 libraries). For the MiSeq sample sheet, each sample was identified by its specific index combination. Libraries were paired-end sequenced with 2x151 bp cycles.

Analysis of obtained sequences. At the end of the run, sequences were aligned to the human genome reference hg19. Generated BAM files were analyzed with the Genome Golden Helix software (Golden Helix, Bozeman, USA). A genetic variation was defined by a Q-score above 30 (except for indel alteration).

\section{Results}

All mutations detected with standard methods were detected with NGS. In the routine diagnosis of lung or colon carcinomas, mutations in KRAS (exon 2), EGFR (exon 18-21), $B R A F$ (exon 15) and HER2 (exon 20) genes are analyzed using three different methods: allelic discrimination for targeted mutations, fragment analysis for the screening of indel variations and Sanger sequencing for non-targeted mutations or characterization of indel abnormalities detected by fragment analysis. All mutation hotspots are analyzed one by one. Over the years, more and more genes and mutation hotspots will need to be explored. For example, exons 3 and 4 of $K R A S$, and exons 2-4 of NRAS and HRAS need to be analyzed before anti-EGFR antibody can be prescribed for colon cancer $(7,8)$. In the first step of our study, we used the Truseq Cancer Panel kit to sequence samples that had already been analyzed in routine diagnosis. We then compared the results obtained by NGS with the results of the routine 

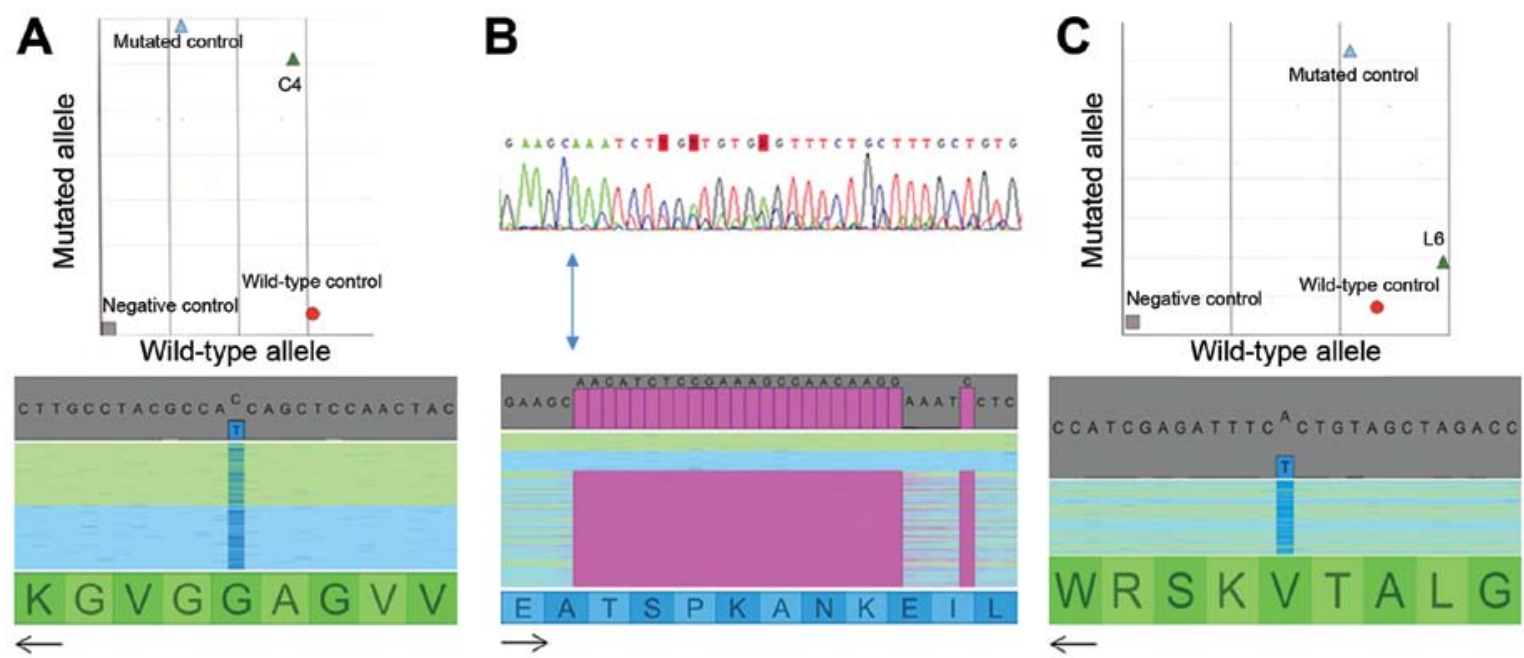

Figure 1. All the mutations detected during routine diagnosis were also detected by NGS. (A) G12D KRAS mutation detected by allelic discrimination (upper panel) and by NGS (lower panel) for patient C4. Orientation of the KRAS gene needs to be completed to obtain the coding sequence. (B) A 24-nt deletion in exon 19 of EGFR obtained with Sanger sequencing (upper panel) for patient L3. Unlike the Sanger method, NGS analysis (lower panel), made it easy to identify the exact deletion (23 nt $+1 \mathrm{nt})$. The double blue arrow shows the start of the deletion. (C) V600E BRAF mutation detected by allelic discrimination (upper panel) and by NGS (lower panel) for patient L6. Orientation of the BRAF gene needs to be completed to obtain the coding sequence. The arrows indicate the orientation of each gene.

Table II. Comparison of results obtained routinely and with NGS.

\begin{tabular}{|c|c|c|c|c|c|c|c|c|}
\hline \multirow[b]{2}{*}{ Patients } & \multicolumn{2}{|c|}{ KRAS } & \multicolumn{2}{|c|}{$B R A F$} & \multicolumn{2}{|c|}{$E G F R$} & \multicolumn{2}{|c|}{ HER2 } \\
\hline & Routine $^{a}$ & NGS & Routine $^{b}$ & NGS & Routine $^{c}$ & NGS & Routine $^{\mathrm{d}}$ & NGS \\
\hline L1 & WT & G12D & WT & WT & WT & 15-nt E19 & WT & WT \\
\hline L2 & WT & WT & WT & WT & 15-nt E19 & 15-nt E19 & WT & WT \\
\hline L3 & WT & WT & WT & WT & 24-nt E19 & 24-nt E19 & WT & WT \\
\hline L4 & WT & WT & WT & WT & L858R & L858R & WT & WT \\
\hline L5 & WT & WT & WT & WT & 15-nt E19 T790M & 15-nt E19 T790M & WT & WT \\
\hline L6 & WT & WT & V600E & V600E & WT & 15-nt E19 & WT & WT \\
\hline L7 & $\mathrm{G} 12 \mathrm{C}$ & $\mathrm{G} 12 \mathrm{C}$ & WT & WT & WT & WT & WT & WT \\
\hline L8 & WT & WT & WT & WT & WT & WT & WT & WT \\
\hline $\mathrm{C} 1$ & WT & WT & WT & V600R & ND & & ND & \\
\hline $\mathrm{C} 2$ & WT & WT & WT & WT & ND & & ND & \\
\hline $\mathrm{C} 3$ & G13D & G13D & WT & WT & ND & & ND & \\
\hline $\mathrm{C} 4$ & G12D & G12D & WT & WT & ND & & ND & \\
\hline $\mathrm{C} 5$ & WT & WT & WT & WT & ND & & ND & \\
\hline C6 & WT & WT & WT & WT & ND & & ND & \\
\hline $\mathrm{C} 7$ & G13D & G13D & WT & WT & ND & & ND & \\
\hline C8 & WT & WT & WT & WT & ND & & ND & \\
\hline C9 & WT & WT & WT & WT & ND & & ND & \\
\hline $\mathrm{C} 10$ & WT & WT & WT & WT & ND & & ND & \\
\hline
\end{tabular}

${ }^{\mathrm{a}}$ Allelic discrimination (codons 12 and 13), ${ }^{\mathrm{b}}$ Allelic discrimination (codon 600), ${ }^{\mathrm{c}}$ Allelic discrimination (codons 719, 790, 858 and 861), fragment analysis and Sanger sequencing (exons 19, 20 and 21), ${ }^{d}$ fragment analysis and Sanger sequencing (exon 20). ND, not determined. Characters in bold show the discordance between routine and NGS analyses.

diagnosis at the same mutational hotspots. All the mutations detected in the routine diagnosis were also detected by NGS (Fig. 1 and Table II). Moreover, mutations not found in routine diagnosis were detected by NGS. These included a $15-n t$ deletion (c.2235_2249delGGAATTAAGAGAAGC) in two lung carcinomas classified as wild-type using routine methods 
(patients L1 and L6). In the L1 sample, another mutation in the KRAS gene (G12D) was also identified. In patient L6, this 15-nt deletion in EGFR was concomitant with a V600E BRAF mutation.

In colon cancer, a 'common' 15-nt deletion in the EGFR gene was detected only with NGS. Up to now, rare mutations of the KRAS gene have not been routinely analyzed in lung carcinomas. In our small population, a Q61H mutation in the $K R A S$ gene was found in the sample L8. This mutation was localized in exon 3, which is not routinely analyzed in lung cancer. No other alteration was found in the routinely analyzed genes (HRAS and NRAS).

In colon cancer, only the genes $K R A S, B R A F$ and very recently $N R A S$ and $H R A S$ are studied. Concerning rare mutations of KRAS, NRAS and HRAS, we detected a Q61K mutation in the NRAS gene in patient C5. As numerous genes were sequenced by the Cancer Panel kit, we analyzed the results obtained for the PIK3CA, HER2 and EGFR genes, which are routinely analyzed in lung carcinomas. No mutations were detected in exon 20 of HER2, or in exons 18,20 or 21 of EGFR. In exon 20 of PIK3CA, an H1047L mutation was detected in patient C9. Concerning exon 19 of EGFR, a 15-nt deletion (the same as that observed in lung carcinomas) was detected in three patients (C4, $\mathrm{C} 6$ and $\mathrm{C} 7)$. As this region was not routinely analyzed for colon cancer, we decided to perform both fragment analysis and Sanger sequencing. Neither fragment analysis, nor Sanger sequencing was able to detect the 15-nt deletion in exon 19 of EGFR in colon cancer (Fig. 2A). In contrast, NGS sequencing detected the deletion in $>8 \%$ of sequenced fragments (Fig. 2B) for one patient. The two other patients harbored the mutation in approximately $4 \%$ of read sequences. Among these three patients, only one did not present a concomitant KRAS mutation.

WGA does not alter the NGS sequencing results. An important limitation in routine diagnosis is the quantity of gDNA extracted from FFPE samples and another paraffin block cannot be obtained in most cases. To counteract this limitation, we tested the impact of Whole Genome Amplification (WGA) on two samples of gDNA obtained from FFPE tissues. We then performed allelic discrimination on non-amplified gDNA and amplified gDNA (Fig. 3A). A KRAS G12C mutation was detected in both the amplified and non-amplified sample from patient L7. For patient L8, no KRAS G12C mutation was observed in either sample. In NGS analysis, the KRAS G12C mutation was also observed in patient L7 (non-amplified and WGA) but not in patient L8 (Fig. 3B). We also analyzed other routinely studied genes to compare the sequences before and after WGA. Whatever the gene analyzed, no point mutation was induced by the WGA (e.g., with the V600E $B R A F$ and L858R EGFR hotpoint mutations in Fig. 3C). Even the rare mutation Q61H of KRAS was detected in both non-amplified and WGA gDNA from patient L8 (Fig. 3D). Moreover, the variant allele fraction was not modified after amplification.

NGS analysis revealed cancer susceptibility SNP and genetic alterations in some genes. The Illumina Cancer Panel kit studies exons with mutation hotpoints of 48 genes. We therefore analyzed all covered sequences for the 8 lung carcinomas and 10 colon carcinomas. Twenty-eight genetic alterations and three SNP related to cancer susceptibility or different protein activities were found (Table III). The most frequently altered gene was TP53 with nine alterations detected in nine patients. Double mutations in the colon cancer susceptibility genes $A P C$ and SMAD4 were detected in two patients (C3 and $\mathrm{C} 8$, respectively), suggesting a familial risk of colon cancer in these patients. For the patient with the APC mutation, we detected a concomitant $c-M E T$ activating mutation E168D. Concerning patient $\mathrm{C} 8$, we found a large number of alterations in different genes (c-KIT, c-MET, FBXW7, FGFR3, FLT3, IDH1, KRAS, $R B 1, S M A D 4$ and TP53), suggesting high genetic instability in this $S M A D 4$ mutated tumor. Moreover, thanks to the nontargeted analysis, we detected two BRAF exon 15 mutations, N581S and V600R, which induce intermediate and strong activation of the protein, respectively. Furthermore, two mutations with unknown impact were detected in PIK3CA and PTEN. Concerning SNP, two patients (L7 and C4) harbored the breast cancer susceptibility ATM F858L SNP, and one patient (C10) had the rare $c$-KIT M541L SNP, which may influence the response to imatinib. Finally, 10 patients ( 8 heterozygotes and 2 homozygotes $\mathrm{H} 472 \mathrm{H}$ ) harbored the KDR Q472H polymorphism, which has been reported to increase tumor microvasculature.

\section{Discussion}

Molecular diagnosis is the current challenge in cancer management. Indeed, with the increased number of targeted therapies and resistance mechanisms developed by cancer cells, the molecular analysis of tumors is a very important task to achieve optimal cancer therapy. Sanger sequencing, even when accompanied by alternon-amplified technologies, such as allelic discrimination or high resolution melting technology, has shown its limits. Today, next-generation sequencing is providing exciting new perspectives. In this study, we tested Truseq Amplicon technology for the analysis of mutation hotspots of 48 genes in gDNA extracted from FFPE samples. All of the mutations detected by routine Sanger sequencing, allelic discrimination or fragment analysis (in KRAS, BRAF, $E G F R$ genes) were also identified with NGS analysis. Moreover, other alterations at the mutation hotspots of the routinely analyzed genes were also detected. These additional alterations included a G12D $K R A S$, a V600R $B R A F$ and a 15-nt deletion in exon 19 of $E G F R$. The additional deletion in the EGFR gene was concomitant with the G12D KRAS mutation in one patient, and with a V600E BRAF mutation in another patient. $K R A S, B R A F$ and $E G F R$ mutations are normally exclusive (9) but concomitant KRAS and EGFR mutations have already been described $(10,11)$. The identification of concomitant mutations should increase with the higher sensitivity of NGS technologies. Nevertheless, as it may be impossible to confirm these 'new' mutations using routine techniques, their clinical relevance and even their existence may be debatable (12). In the same way, some mutations are detected by NGS in very few of the read sequences. For example, the 15-nt deletion found in three colon carcinomas was detected in less than $8 \%$ of the read sequences, and among these three colon carcinomas, one had no KRAS/BRAF mutation, one had a concomitant G12D KRAS mutation, and one also had 
A

Fragment analysis
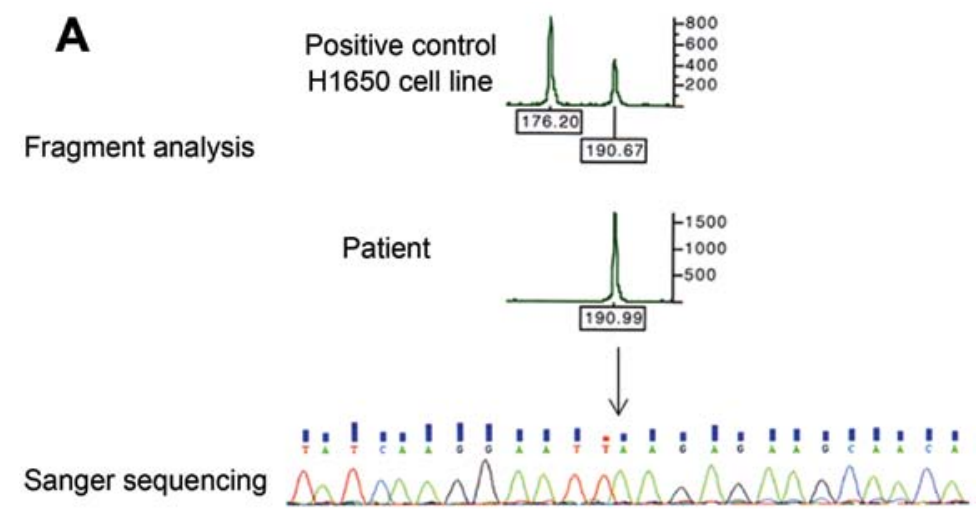

\section{B}

NGS sequencing

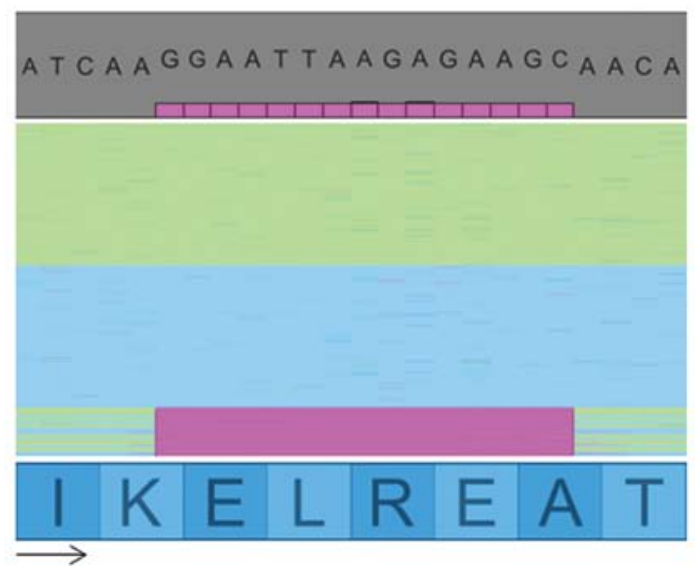

Figure 2. A 15-nt deletion detected in exon 19 of $E G F R$ from colon carcinomas. (A) Fragment analysis and Sanger sequencing of $E G F R$ exon 19 in a colon carcinoma. No alteration was observed in the region. (B) In the same sample analyzed with NGS, a 15-nt deletion (c.2235_2249delGGAATTAAGAGAAGC) was observed in about $8 \%$ of the read sequences. The arrow indicates the orientation of the gene.

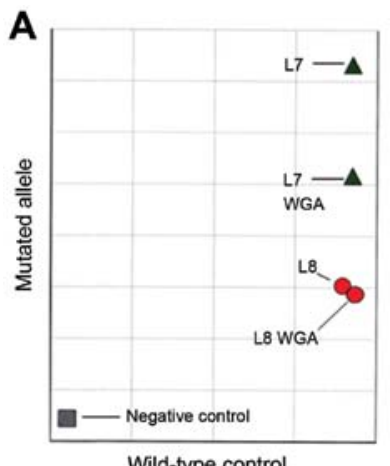

Wild-type control

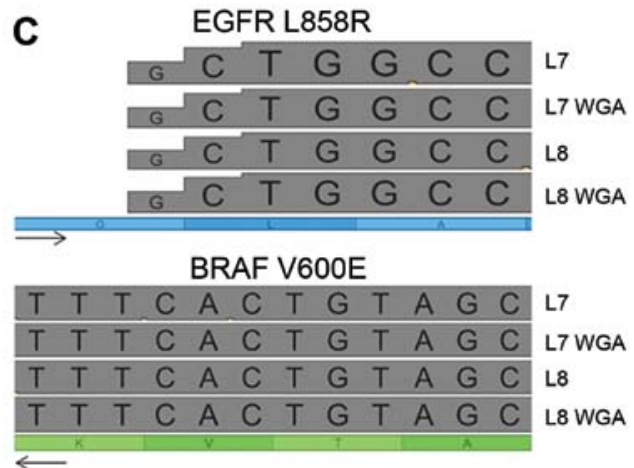

B
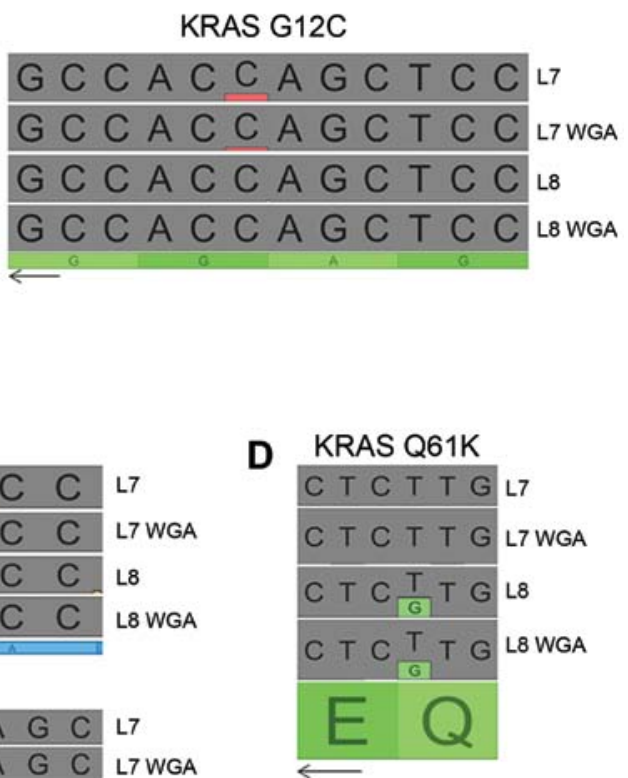

Figure 3. Whole Genome Amplification (WGA) of gDNA from FFPE did not alter the mutation profile of patients. (A) Routine G12C KRAS allelic discrimination of gDNA from patients L7 and L8 before and after WGA. (B) Analysis, by NGS, of KRAS exon 2 for the same patients. The profiles obtained with NGS technology are the same as with routine allelic discrimination: L7 WGA signal was lower than the non-amplified L7 signal. Nevertheless, this minor difference would not have affected the diagnosis. (C) WGA did not create genetic alterations, for example with the V600E BRAF and L858R EGFR hotpoint mutations. (D) The rare Q61K KRAS mutation observed in patient L8 was conserved by WGA. The arrows indicate the orientation of each gene. 
Table III. Exonic SNP and genetic alterations in other analyzed genes.

\begin{tabular}{|c|c|c|c|c|}
\hline Genes & Nucleotide variation & $\begin{array}{l}\text { Protein sequence } \\
\text { variation }\end{array}$ & Patients & Impact \\
\hline \multirow[t]{2}{*}{$A P C$} & c. $2626 \mathrm{C} \rightarrow \mathrm{T}$ & $\mathrm{R} 876 \mathrm{X}$ & $\mathrm{C} 3$ & Loss of function (familial mutation) \\
\hline & c. $3944 \mathrm{C} \rightarrow \mathrm{T}$ & S1315X & $\mathrm{C} 3$ & Loss of function (somatic mutation) (26) \\
\hline ATM & c. $2572 \mathrm{~T} \rightarrow \mathrm{C}$ & F858L & $\mathrm{L} 7, \mathrm{C} 4$ & Breast cancer susceptibility SNP (23) \\
\hline \multirow[t]{2}{*}{$B R A F$} & c. $1742 \mathrm{~A} \rightarrow \mathrm{G}$ & N581S & $\mathrm{C} 2$ & Intermediate activated (27) \\
\hline & c.1798_1799GT $\rightarrow$ AG & V600R & $\mathrm{C} 1$ & Strongly activated (28) \\
\hline \multirow[t]{2}{*}{$c-K I T$} & c. $1621 \mathrm{~A} \rightarrow \mathrm{C}$ & M541L & $\mathrm{C} 10$ & SNP with a potential effect on imatinib response (29) \\
\hline & c. $2146 \mathrm{G} \rightarrow \mathrm{A}$ & $\mathrm{D} 716 \mathrm{~N}$ & $\mathrm{C} 8$ & Possible resistance to imatinib (24) \\
\hline \multirow[t]{2}{*}{$c-M E T$} & c. $504 \mathrm{G} \rightarrow \mathrm{T}$ & E168D & $\mathrm{C} 3$ & Activated (19) \\
\hline & c. $1156 \mathrm{C} \rightarrow \mathrm{A}$ & L386I & $\mathrm{C} 8$ & Unknown (never observed) \\
\hline$F B X W 7$ & c. $832 \mathrm{C} \rightarrow \mathrm{T}$ & $\mathrm{R} 278 \mathrm{X}$ & $\mathrm{C} 8$ & Uncertain significance (30) \\
\hline$F G F R 3$ & c.1196_1197GC $\rightarrow$ AG & R399H & $\mathrm{C} 8$ & Unknown (31) \\
\hline FLT3 & c. $2039 \mathrm{C} \rightarrow \mathrm{T}$ & A680V & $\mathrm{C} 8$ & Activated (32) \\
\hline$I D H 1$ & c. $290 \mathrm{G} \rightarrow \mathrm{A}$ & G97V & $\mathrm{C} 8$ & Loss of wild-type function (33) \\
\hline$K D R$ & c. $1416 \mathrm{~A} \rightarrow \mathrm{T}$ & Q472H & $\begin{array}{l}\text { H: L1-L3, L5, } \\
\text { L7-L8, C5-C6 } \\
\text { O: C7, C9 }\end{array}$ & Increased activity SNP (25) \\
\hline$K R A S$ & c. $408 \mathrm{~T} \rightarrow \mathrm{A}$ & $\mathrm{S} 136 \mathrm{~K}$ & $\mathrm{C} 8$ & Unknown \\
\hline$P I K 3 C A$ & c. $2176 \mathrm{G} \rightarrow \mathrm{A}$ & E726K & $\mathrm{C} 2$ & Unknown (34) \\
\hline PTEN & c. $.563 \mathrm{~A} \rightarrow \mathrm{T}$ & D187V & L1 & Unknown \\
\hline \multirow[t]{2}{*}{$R B 1$} & c.2074_2075insATGA & Y692FsX2 & $\mathrm{L} 2, \mathrm{~L} 5$ & Loss of function \\
\hline & c. $2119 \mathrm{~T} \rightarrow \mathrm{C}$ & S707P & $\mathrm{C} 8$ & Unknown \\
\hline \multirow[t]{2}{*}{$S M A D 4$} & c. $1009 \mathrm{G} \rightarrow \mathrm{A}$ & E337K & $\mathrm{C} 8$ & Unknown \\
\hline & c. $1082 \mathrm{G} \rightarrow \mathrm{A}$ & $\mathrm{R} 361 \mathrm{H}$ & $\mathrm{C} 8$ & Loss of function (35) \\
\hline \multirow[t]{9}{*}{ TP53 } & c. $310 \mathrm{C} \rightarrow \mathrm{T}$ & Q104X & L1 & Unknown $^{\mathrm{a}}$ \\
\hline & c. $523 \mathrm{C} \rightarrow \mathrm{T}$ & $\mathrm{R} 175 \mathrm{~V}$ & $\mathrm{C} 8$ & Unknown \\
\hline & c. $527 \mathrm{G} \rightarrow \mathrm{T}$ & $\mathrm{C} 176 \mathrm{~F}$ & L5 & Partially functional/deleterious ${ }^{\mathrm{a}}$ \\
\hline & c. $536 \mathrm{~A} \rightarrow \mathrm{G}$ & H179R & $\mathrm{C} 3$ & Non-functional/deleterious ${ }^{\mathrm{a}}$ \\
\hline & IVS5+2T $\rightarrow \mathrm{G}$ & G187Fs & $\mathrm{C} 1$ & Unknown \\
\hline & c.709A $\rightarrow \mathrm{C}$ & M237L & $\mathrm{C} 10$ & Partially functional/deleterious $\mathrm{s}^{\mathrm{a}}$ \\
\hline & c. $743 \mathrm{G} \rightarrow \mathrm{A}$ & R248Q & C6 & Non-functional/deleterious $\mathrm{s}^{\mathrm{a}}$ \\
\hline & c. $742 \mathrm{C} \rightarrow \mathrm{T}$ & R248W & $\mathrm{C} 5$ & Non-functional/deleterious ${ }^{\mathrm{a}}$ \\
\hline & c. $830 \mathrm{G} \rightarrow \mathrm{T}$ & $\mathrm{C} 277 \mathrm{~F}$ & $\mathrm{C} 7$ & Non-functional/deleterious ${ }^{\mathrm{a}}$ \\
\hline
\end{tabular}

${ }^{\mathrm{a}}$ From IARC database (36).

a G13D KRAS mutation. This observation is quite disturbing, and raises two questions: was the 15-nt deletion true, and if so, was this alteration clinically relevant given the small number detected. Today, the only way to have an answer would be to treat these patients with EGFR tyrosine kinase inhibitors or to observe anti-EGFR antibody resistance in these patients. To date, only patients with KRAS (13), HRAS or NRAS mutations $(7,8)$ can be diagnosed as immediately resistant. Concerning our three colon carcinomas, two may benefit from treatment with EGFR TKI as the G13D KRAS mutation does not seem to interfere with the inhibition of the EGFR pathway (14).

With the increase in the number of genes to be analyzed for molecular diagnosis, the quantity of gDNA obtained from FFPE tissues will rapidly become a major problem, especially for lung carcinomas. In this work, we tested Whole Genome Amplification in two lung carcinomas and analyzed the 
resulting samples by NGS. The genetic profile obtained before and after WGA was qualitatively the same and quantitatively close. Indeed, only the intensity of the G12C KRAS mutation in patient L7 was slightly lower in the amplified sample. The strong similarity between amplified and non-amplified samples is in accordance in very recent studies, which showed that WGA can be safely used for diagnosis $(15,16)$. Moreover, through this experiment, we showed that Truseq Amplicon technology is compatible with samples treated by WGA.

Among the genes or codons studied in the panel but not analyzed in routine molecular diagnosis, we detected 27 different alterations in 14 genes. Of these, 9 were detected in the TP53 gene, which is the most frequently altered gene in cancer (17). Eight mutations were in the DNA binding domain of the protein, indicating that these mutations are deleterious. One mutation occurred in a splice site, inducing a frameshift that may not be deleterious (18). We detected 2 genes with a double mutation, $A P C$ and $S M A D 4$. The presence of two mutations in these two colon cancer predisposition genes indicated that these patients could have been members of families with a high risk of colon cancer. Both patients harbored mutations in the c-MET genes. The APC mutated patient had the activating mutation E168D (19), making him/her eligible for crizotinib therapy, which is generally used in lung cancer (20). Concerning the SMAD4 mutated tumor, we detected eight other altered genes, suggesting high genetic instability in this tumor type $(21,22)$. The impact of most of these alterations is unknown. Nevertheless, the activating A680V mutation of FLT3 may be targeted by anti-FLT3 therapies currently in clinical development for the treatment of leukemia.

Three SNP modifying protein sequences were found. ATM F858L polymorphism, detected in two patients, is associated with an increased risk of breast cancer (23), but the small number of patients in our study does not allow us to draw any conclusions with regard to the predisposition for colon and lung cancer. Then, $c-K I T$ M541L polymorphism was found in only one patient. The impact of this polymorphism in not known, but it has been suggested that it may affect the response to imatinib (24). Finally, KDR Q472H polymorphism was the most interesting alteration. Indeed, tumors with histidine show higher vascularization than do tumors with glutamine (25). In the Caucasian population, the frequency of each genotype is 58, 36 and 6\% for Q472Q, Q472H and H472H, respectively. In our small population of tumors $(n=18)$, we found enrichment of the histidine allele in $55.5 \%$ of our tumors $(44.5 \% \mathrm{Q} / \mathrm{Q}$, $44.5 \% \mathrm{Q} / \mathrm{H}$ and $11 \% \mathrm{H} / \mathrm{H})$. In lung carcinomas we observed an enrichment of heterozygous tumors $(75 \%)$, whereas in colon, the enrichment concerned homozygous $\mathrm{H} / \mathrm{H}$ tumors. Moreover, during the analysis, we found that the presence of each allele was not 50/50 in heterozygous tumors, but varied from 9 to $96 \%$ of the read sequences. This raises the question of true polymorphism or a selection of tumor cells with a high angiogenic capacity. To answer this question, it would be necessary to analyze the constitutive DNA of each patient. According to the study by Glubb et al, patients with heterozygous or homozygous histidine tumors could be more sensitive to inhibiting treatments of VEGFR2 or to bevacizumab.

In conclusion, the analysis by NGS of FFPE lung and colon carcinomas identified the alterations highlighted by routine molecular diagnosis techniques. Thanks to its higher sensitivity, NGS analysis revealed new mutations that were not detected routinely. The impossibility to confirm the presence of these mutations by another technology is problematic, and the only way to answer this question is by conducting clinical trials that compare treatments of patients diagnosed by routine techniques or by NGS. Finally, the use of NGS in routine practice could revolutionize the management of cancer patients. Indeed, simultaneous analysis of numerous genes could identify drugsensitive alterations generally observed in other cancer types (for example a $c$-MET alteration in a colon carcinoma that would be treated with crizotinib in lung cancer). Nevertheless, high throughput studies that combine NGS analysis and clinical trials need to be performed before NGS analysis can be generalized in routine molecular diagnosis.

\section{Acknowledgements}

We thank Philip Bastable for editing the manuscript.

\section{References}

1. Lynch TJ, Bell DW, Sordella R, Gurubhagavatula S, Okimoto RA, Brannigan BW, Harris PL, Haserlat SM, Supko JG, Haluska FG, Louis DN, Christiani DC, Settleman J and Haber DA: Activating mutations in the epidermal growth factor receptor underlying responsiveness of non-small-cell lung cancer to gefitinib. N Engl J Med 350: 2129-2139, 2004.

2. Di Nicolantonio F, Martini M, Molinari F, Sartore-Bianchi A, Arena S, Saletti P, De Dosso S, Mazzucchelli L, Frattini M, Siena $S$ and Bardelli A: Wild-type BRAF is required for response to panitumumab or cetuximab in metastatic colorectal cancer. $\mathrm{J}$ Clin Oncol 26: 5705-5712, 2008.

3. Chapman PB, Hauschild A, Robert C, Haanen JB, Ascierto P, Larkin J, Dummer R, Garbe C, Testori A, Maio M, Hogg D, Lorigan P, Lebbe C, Jouary T, Schadendorf D, Ribas A, O'Day SJ, Sosman JA, Kirkwood JM, Eggermont AM, Dreno B, Nolop K, Li J, Nelson B, Hou J, Lee RJ, Flaherty KT, McArthur GA and BRIM-3 Study Group: Improved survival with vemurafenib in melanoma with BRAF V600E mutation. N Engl J Med 364: 2507-2516, 2011.

4. Carvajal RD, Antonescu CR, Wolchok JD, Chapman PB, Roman RA, Teitcher J, Panageas KS, Busam KJ, Chmielowski B, Lutzky J, Pavlick AC, Fusco A, Cane L, Takebe N, Vemula S, Bouvier N, Bastian BC and Schwartz GK: KIT as a therapeutic target in metastatic melanoma. JAMA 305: 2327-2334, 2011.

5. Lee LG, Connell CR and Bloch W: Allelic discrimination by nick-translation PCR with fluorogenic probes. Nucleic Acids Res 21: 3761-3766, 1993.

6. Liew M, Pryor R, Palais R, Meadows C, Erali M, Lyon E and Wittwer C: Genotyping of single-nucleotide polymorphisms by high-resolution melting of small amplicons. Clin Chem 50: 1156-1164, 2004

7. Douillard JY, Oliner KS, Siena S, Tabernero J, Burkes R, Barugel M, Humblet Y, Bodoky G, Cunningham D, Jassem J, Rivera F, Kocákova I, Ruff P, Błasińska-Morawiec M, Smakal M, Canon JL, Rother M, Williams R, Rong A, Wiezorek J, Sidhu R and Patterson SD: Panitumumab-FOLFOX4 treatment and RAS mutations in colorectal cancer. N Engl J Med 369: 1023-1034, 2013.

8. Fornaro L, Lonardi S, Masi G, Loupakis F, Bergamo F, Salvatore L, Cremolini C, Schirripa M, Vivaldi C, Aprile G, Zaniboni A, Bracarda S, Fontanini G, Sensi E, Lupi C, Morvillo M, Zagonel V and Falcone A: FOLFOXIRI in combination with panitumumab as first-line treatment in quadruple wild-type (KRAS, NRAS HRAS, BRAF) metastatic colorectal cancer patients: a phase II trial by the Gruppo Oncologico Nord Ovest (GONO). Ann Oncol 24: 2062-2067, 2013.

9. Reddi HV: Mutations in the EGFR pathway: clinical utility and testing strategies. Clin Lab News 39: 14-16, 2013.

10. Schmid K, Oehl N, Wrba F, Pirker R, Pirker C and Filipits M: EGFR/KRAS/BRAF mutations in primary lung adenocarcinomas and corresponding locoregional lymph node metastases. Clin Cancer Res 15: 4554-4560, 2009. 
11. Tuononen K, Mäki-Nevala S, Sarhadi VK, Wirtanen A, Rönty M, Salmenkivi K, Andrews JM, Telaranta-Keerie AI, Hannula S, Lagström S, Ellonen P, Knuuttila A and Knuutila S: Comparison of targeted next-generation sequencing (NGS) and real-time PCR in the detection of EGFR, KRAS, and BRAF mutations on formalin-fixed, paraffin-embedded tumor material of non-small cell lung carcinoma-superiority of NGS. Genes Chromosomes Cancer 52: 503-511, 2013.

12. McCourt CM, McArt DG, Mills K, Catherwood MA, Maxwell P, Waugh DJ, Hamilton P, O'Sullivan JM and Salto-Tellez M: Validation of next generation sequencing technologies in comparison to current diagnostic gold standards for BRAF, EGFR and KRAS mutational analysis. PLoS One 8: e69604, 2013.

13. Misale S, Yaeger R, Hobor S, Scala E, Janakiraman M, Liska D, Valtorta E, Schiavo R, Buscarino M, Siravegna G, Bencardino K, Cercek A, Chen CT, Veronese S, Zanon C, Sartore-Bianchi A, Gambacorta M, Gallicchio M, Vakiani E, Boscaro V, Medico E, Weiser M, Siena S, Di Nicolantonio F, Solit D and Bardelli A: Emergence of KRAS mutations and acquired resistance to anti-EGFR therapy in colorectal cancer. Nature 486: 532-536, 2012.

14. Tejpar S, Celik I, Schlichting M, Sartorius U, Bokemeyer C and Van Cutsem E: Association of KRAS G13D tumor mutations with outcome in patients with metastatic colorectal cancer treated with first-line chemotherapy with or without cetuximab. J Clin Oncol 30: 3570-3577, 2012.

15. Della Starza I, De Novi LA, Nunes V, Del Giudice I, Ilari C, Marinelli M, Negulici AD, Vitale A, Chiaretti S, Foà R and Guarini A: Whole-genome amplification for the detection of molecular targets and minimal residual disease monitoring in acute lymphoblastic leukaemia. Br J Haematol 165: 341-348, 2014.

16. Hasmats J, Gréen H, Orear C, Validire P, Huss M, Käller M and Lundeberg J: Assessment of whole genome amplification for sequence capture and massively parallel sequencing. PLoS One 9: e84785, 2014.

17. Vogelstein B, Sur S and Prives C: p53: the most frequently altered gene in human cancers. Nat Educat 3: 6, 2010.

18. Végran F, Rebucci M, Chevrier S, Cadouot M, Boidot $R$ and Lizard-Nacol S: Only missense mutations affecting the DNA binding domain of p53 influence outcomes in patients with breast carcinoma. PLoS One 8: e55103, 2013.

19. Ma PC, Jagadeeswaran R, Jagadeesh S, Tretiakova MS, Nallasura V, Fox EA, Hansen M, Schaefer E, Naoki K, Lader A, Richards W, Sugarbaker D, Husain AN, Christensen JG and Salgia R: Functional expression and mutations of c-Met and its therapeutic inhibition with SU11274 and small interfering RNA in non-small cell lung cancer. Cancer Res 65: 1479-1488, 2005.

20. Tanizaki J, Okamoto I, Okamoto K, Takezawa K, Kuwata K, Yamaguchi $\mathrm{H}$ and Nakagawa K: MET tyrosine kinase inhibitor crizotinib (PF-02341066) shows differential antitumor effects in non-small cell lung cancer according to MET alterations. J Thorac Oncol 6: 1624-1631, 2011.

21. Markowitz S, Wang J, Myeroff L, Parsons R, Sun L, Lutterbaugh J, Fan RS, Zborowska E, Kinzler KW, Vogelstein B, et al: Inactivation of the type II TGF-beta receptor in colon cancer cells with microsatellite instability. Science 268: 1336-1338, 1995.

22. Woodford-Richens KL, Rowan AJ, Gorman P, Halford S, Bicknell DC, Wasan HS, Roylance RR, Bodmer WF and Tomlinson IP: SMAD4 mutations in colorectal cancer probably occur before chromosomal instability, but after divergence of the microsatellite instability pathway. Proc Natl Acad Sci USA 98: 9719-9723, 2001

23. Struewing JP: Genomic approaches to identifying breast cancer susceptibility factors. Breast Dis 19: 3-9, 2004.
24. Debiec-Rychter M, Cools J, Dumez H, Sciot R, Stul M, Mentens N, Vranckx H, Wasag B, Prenen H, Roesel J, Hagemeijer A, Van Oosterom A and Marynen P: Mechanisms of resistance to imatinib mesylate in gastrointestinal stromal tumors and activity of the PKC412 inhibitor against imatinib-resistant mutants. Gastroenterology 128: 270-279, 2005.

25. Glubb DM, Cerri E, Giese A, Zhang W, Mirza O, Thompson EE, Chen P, Das S, Jassem J, Rzyman W, Lingen MW, Salgia R, Hirsch FR, Dziadziuszko R, Ballmer-Hofer K and Innocenti F: Novel functional germline variants in the VEGF receptor 2 gene and their effect on gene expression and microvessel density in lung cancer. Clin Cancer Res 17: 5257-5267, 2011.

26. Albuquerque $C$, Breukel $C$, van der Luijt R, Fidalgo $P$, Lage $P$, Slors FJ, Leitão CN, Fodde R and Smits R: The 'just-right' signaling model: APC somatic mutations are selected based on a specific level of activation of the beta-catenin signaling cascade. Hum Mol Genet 11: 1549-1560, 2012.

27. Fratev FF and Jónsdóttir SO: An in silico study of the molecular basis of B-RAF activation and conformational stability. BMC Struct Biol 9: 47, 2009.

28. Klein O, Clements A, Menzies AM, O'Toole S, Kefford RF and Long GV: BRAF inhibitor activity in V600R metastatic melanoma. Eur J Cancer 49: 1073-1079, 2013.

29. Grabellus F, Worm K, Sheu SY, Siffert W, Schmid KW and Bachmann HS: The prevalence of the c-kit exon 10 variant, M541L, in aggressive fibromatosis does not differ from the general population. J Clin Pathol 64: 1021-1024, 2011.

30. Davis H, Lewis A, Behrens A and Tomlinson I: Investigation of the atypical FBXW7 mutation spectrum in human tumours by conditional expression of a heterozygous propellor tip missense allele in the mouse intestines. Gut 63: 792-799, 2014

31. Imielinski M, Berger AH, Hammerman PS, Hernandez B, Pugh TJ, Hodis E, Cho J, Suh J, Capelletti M, Sivachenko A Sougnez C, Auclair D, Lawrence MS, Stojanov P, Cibulskis K, Choi K, de Waal L, Sharifnia T, Brooks A, Greulich H, Banerji S, Zander T, Seidel D, Leenders F, Ansén S, Ludwig C, Engel-Riedel W, Stoelben E, Wolf J, Goparju C, Thompson K, Winckler W, Kwiatkowski D, Johnson BE, Jänne PA, Miller VA, Pao W, Travis WD, Pass HI, Gabriel SB, Lander ES, Thomas RK, Garraway LA, Getz G and Meyerson M: Mapping the hallmarks of lung adenocarcinoma with massively parallel sequencing. Cell 150: 1107-1120, 2012.

32. Piccaluga PP, Bianchini M and Martinelli G: Novel FLT3 point mutation in acute myeloid leukaemia. Lancet Oncol 4: 604 , 2003.

33. Ward PS, Cross JR, Lu C, Weigert O, Abel-Wahab O, Levine RL, Weinstock DM, Sharp KA and Thompson CB: Identification of additional IDH mutations associated with oncometabolite R(-)-2hydroxyglutarate production. Oncogene 31: 2491-2498, 2012.

34. Jaiswal BS, Janakiraman V, Kljavin NM, Chaudhuri S, Stern HM Wang W, Kan Z, Dbouk HA, Peters BA, Waring P, Dela Vega T, Kenski DM, Bowman KK, Lorenzo M, Li H, Wu J, Modrusan Z, Stinson J, Eby M, Yue P, Kaminker JS, de Sauvage FJ, Backer JM and Seshagiri S: Somatic mutations in p85alpha promote tumorigenesis through class IA PI3K activation. Cancer Cell 16: 463-474, 2009.

35. Miyaki M, Iijima T, Konishi M, Sakai K, Ishii A, Yasuno M, Hishima T, Koike M, Shitara N, Iwama T, Utsunomiya J, Kuroki T and Mori T: Higher frequency of Smad4 gene mutation in human colorectal cancer with distant metastasis. Oncogene 18: 3098-3103, 1999.

36. Petitjean A, Mathe E, Kato S, Ishioka $C$, Tavtigian SV, Hainaut $P$ and Olivier M: Impact of mutant p53 functional properties on TP53 mutation patterns and tumor phenotype: lessons from recent developments in the IARC TP53 database. Hum Mutat 28: 622-629, 2007. 